\title{
PENGEMBANGAN MODEL OPTIMASI ARTIFICIAL NEURAL NETWORK PADA PENJADWALAN PRODUKSI SNACK TORTILLA
}

\author{
Aldi Yoga Pradana, Widya Setiafindari \\ Program Studi Teknik Industri Universitas Teknologi Yogyakarta \\ aldiyogapradana98@.com, widyasetia@uty.ac.id
}

\begin{abstract}
Production on May 2019, PT X produced 29,159 $\mathrm{kg}$ of Tortillas to be marketed domestically and abroad. The large amount of production shows the high consumer interest in Tortilla, which makes PT $X$ produce large quantities in 1 month. Production of 29,159 kg was completed in 3 weeks with 3 shifts in 7 working days in the first and third week, and 6 working days in the second week. Inaccurate production planning makes Tortilla production exceed warehouse capacity, indicating that the production process is still running even though the number in June is as much as 17,346 $\mathrm{kg}$ and 26,835 kg in July resulting in overproduction of 6\% in May 2019 and 15\% in June 2019 so that there was an increase in July 2019 to 50\%. The implementations of the Artificial Neural Network (ANN) method based on Particle Swarm Optimization (PSO) using the Steepest Ascent Hill Climbing Algorithm (SAHC) areoptimize the final mean flow time by 51\%, reduction in makespan by 0.5 in MayJune and 0.1 in July, and a reduction in lateness by $13 \%$ after reprocessing results in an optimization that can overcome the problem of overproduction.
\end{abstract}

Keywords: overproduction, Makespan, ANN-PSO-SAHC

\begin{abstract}
Abstrak
Pada produksi Mei 2019, PT X memproduksi $29.159 \mathrm{~kg}$ Tortilla untuk dipasarkan di dalam dan luar negeri. Jumlah produksi yang besar menunjukkan tingginya minat konsumen terhadap Tortilla, yang membuat PT X memproduksi dalam jumlah banyak dalam 1 bulan. Produksi $29.159 \mathrm{~kg}$ diselesaikan dalam 3 minggu dengan 3 shift dalam 7 hari kerja pada minggu pertama dan ketiga, dan 6 hari kerja pada minggu kedua. Perencanaan produksi yang tidak akurat membuat produksi Tortilla melebihi kapasitas gudang, hal ini menandakan proses produksi masih berjalan meskipun pada bulan Juni sebanyak $17.346 \mathrm{~kg}$ dan $26.835 \mathrm{~kg}$ pada bulan Juli mengakibatkan over produksi sebesar $6 \%$ pada Mei 2019 dan 15\% pada Juni 2019. Sehingga terjadi peningkatan pada Juli 2019 menjadi 50\%. Implementasi metode Artificial Neural Network (ANN) berbasis Particle Swarm Optimization (PSO) menggunakan Steepest Ascent Hill Climbing Algorithm (SAHC) mengoptimalkan waktu aliran ratarata akhir sebesar $51 \%$, pengurangan makespan sebesar 0,5 pada bulan Mei-Juni dan 0,1 pada bulan Juli, dan penurunan keterlambatan sebesar $13 \%$ setelah pemrosesan ulang menghasilkan pengoptimalan yang dapat mengatasi masalah produksi berlebih.
\end{abstract}

Kata kunci:Overproduction, Makespan, ANN-PSO-SAHC

\section{PENDAHULUAN}

Penjadwalan produksi dilakukan agar membantu perusahaan dalam mempersiapkan produk yang hendak diproduksi. Kegiatan produksi dapat berjalan lancar apabila dipersiapkan dengan baik. Kegiatan produksi yang sudah optimal dapat menjadi salah satu kendala baru apabila tidak disesuaikan dengan kebutuhan produksi saat ini. Penjadwalan yang teroptimasi dapat menjadi solusi dalam mengatasi masalah tersebut. Metode yang digunakan beragam dan dapat disesuaikan dengan kebutuhan solusi masalah.

Permintaan pasar yang selalu berubahubah mengakibatkan bagian produksi harus tetap memproduksi dengan hasil forecasting agar dapat memiliki stock yang cukup apabila terjadi peningkatan permintaan mendadak. Permasalahan overproduction yang terjadidan jadwal produksi yang sudah ditetapkan dapat dioptimalkan dengan cara memodelkan penjadwalan produksi. 
Solusi permasalahan overproduction untuk mengatasi demand yang sering berubah setiap saat dengan penjadwalan produksi yaitu dengan memodelkan penjadwalan produksi dengan Artificial Neural Network (ANN) berbasis Particle Swarm Optimization (PSO)pada penjadwalan produksi Tortilla. Hasil dari pengoptimalan dilanjutkan menggunakan Algoritma Steepest Ascent Hill Climbing (SAHC) untuk menemukan solusi yang lebih optimal untuk penjadwalan produksi Tortilla yang akan datang.

Penelitian menggunakan pendekatan

Artificial Neural Network pernah dilakukan untuk menerapkan sistem penjadwalan manual yang masih terdapat beberapa produk yang terlewati sehingga menyebabkan keterlambatan dalam proses produksi (Rachman, 2018), menggabungkan model Artificial Neural Network berbasis Particle Swarm Optimization untuk prediksi laju inflasi (Raharjo,2013), mengembangkan model optimasi menggunakan Algoritma Steepest Ascent Hill Climbing agar hasil perhitungan dapat dikembangan dengan menambahkan constraint dalam pembuatan jadwal, dan penambahan fungsi yang mampu menyelesaikan proses penjadwalan tanpa melakukan pengecekan ulang solusi jadwal yang telah diproses (Saifullah, 2015).

Metode Artificial Neural Network dapat mempermudah perusahaan dalam mengetahui perubahan penjadwalan apabila terjadi perubahan demand yang fluktuatif yang sering berubah setiap saat. Artificial Neural Network adalah salah satu contoh implementasi ilmu Artificial Intelligence yang membahas mengenai penerapan secara online dan realtime sehingga memudahkan pemantauan kebutuhan perusahaan, pada bagian produksi setiap saat.

Pemodelan terhadap penjadwalan produksi dapat dilanjutkan dengan metode Particle Swarm Optimization (PSO) yang memiliki kecepatan partikel dalam ruang pencarian dan bergerak dengan kecepatan dinamis, partikel memiliki kencenderungan untuk bergerak menuju daerah pencarian yang lebih baik selama proses pencarian (Muhamad dkk, 2017). Particle Swarm Optimization (PSO) telah digunakan sebagai teknik yang efektif di berbagai bidang termasuk dalam pemilihan fitur pengambilan keputusan (Xue dkk, 2012) Beberapa penelitian serupa yang menggunakan Particle Swarm Optimization dalam penjadwalan produksi antara lain Mahmudy (2014), Putamawa (2014), Ali dkk (2018), Chopra dkk (2019), dan Moghaddam dkk (2019). Selain itu, penelitian terhadap Steepest Ascent Hill Climbing dilakukan juga oleh Putranto (2012) dan Shaifullah (2015).

Pemodelan penjadwalan produksi dapat dioptimalkan dengan Artificial Neural Network berbasis Particle Swarm Optimization menggunakan Steepest Ascent Hill Climbing (ANN-PSO-SAHC) pada divisi Tortilla untuk menghindari overproduction, sehingga dapat menghasilkan jadwal produksi yang baru terhadap hasil forecasting MPP dari PPIC. Jadwal yang sudah dioptimalkan dapat digunakan untuk mengatasi overproduction dengan produksi disesuaikan dengan kebutuhan pasar dan kemampuan kapasitas gudang.

\section{TINJAUAN PUSTAKA}

Penjadwalan adalah kegiatan pengalokasian sumber-sumber atau mesinmesin yang ada untuk menjalankan sekumpulan tugas dalam jangka waktu tertentu (Baker, 2013). Penjadwalan juga bisa diartikan proses pengurutan pembuatan produk secara menyeluruh pada beberapa mesin (Conway, 2003).

Elemen dalam penjadwalan menurut Sumayang (2003), penjadwalan adalah mengatur pendayagunaan kapasitas dan sumber daya yang tersedia melalui aktivitas tugas. Perencanaan fasilitas dan perencanaan agregat akan diikuti oleh penjadwalan yang merupakan suatu keputusan dengan karakteristik sebagai berikut:

1. Penjadwalan atau scheduling dibuat untuk jangka waktu pendek, yaitu untuk beberapa jam, minggu atau bulan.

2. Penjadwalan atau scheduling mempunyai tujuan untuk mencapai beberapa hal seperti :
a. Efisiensi yang tinggi
b. Persediaan atau inventori sedikit
c. Kepuasan pelanggan. 
Menurut Ginting (2007) mengidentifikasikan beberapa tujuan dari aktivitas penjadwalan sebagai berikut:

1. Meningkatkan penggunaan sumberdaya atau mengurangi waktu tunggunya, sehingga total waktu proses dapat berkurang, dan produktivitasnya dapat meningkat.

2. Mengurangi persediaan barang setengah jadi atau mengurangi sejumlah pekerjaan yang menunggu dalam antrian ketika sumberdaya yang ada masih mengerjakan tugas yang lain. Teori Baker mengatakan, jika aliran kerja suatu jadwal konstan, maka antrian yang mengurangi rata-rata waktu alir akan mengurangi rata-rata persediaan barang setegah jadi.

3. Mengurangi beberapa kelambatan pada pekerjaan yang mempunyai batas waktu penyelesaian sehingga akan meminimalisasi biaya kelambatan.

4. Membantu pengambilan keputusan mengenai perencanaan kapasitas pabrik dan jenis kapasitas yang dibutuhkan sehingga penambahan biaya yang mahal dapat dihindari.

Istilah-istilah lain dalam penentuan penjadwalan memiliki beberapa hal penting menurut (Hana dan Newman, 2001) yaitu:

1. Critical Ratio (CR) merupakan waktu sampai batas waktu pekerjaan selesai dimana waktu sekarang dibagi dengan waktu proses sampai menyelesaikan suatu pekerjaan tersebut. Pada critical ratio, urutan pekerjaan yang akan diproduksi berdasarkan nilai CR terkecil sampai nilai CR tertinggi

2. Shortest processing Time (SPT) memprioritaskan pekerjaan berdasarkan waktu proses yang paling pendek. Aturan ini secara umum meningkatkan efisiensi dan mempunyai dampak pada aliran kas perusahaan. Secara matematis dapat dibuktikan bahwa SPT dapat meminimasi rata-rata waktu penyelesaian pekerjaan (flow time), atau rata-rata waktu yang dihabiskan oleh pekerjaan pada stasiun kerja, termasuk waktu menunggu dan waktu pemrosesan. Waktu penyelesaian (flow time) sangat erat kaitannya dengan tingkat persediaan. Meminimalisasi flow time mempunyai dampak yang positif terhadap pencapaian batas waktu pekerjaan selesai

3. Longest Processing Time (LPT) merupakan lawan dari SPT dimana teknik ini tidak direkomendasikan baik untuk pencapaian yang efisien dan terhadap batas waktu penyerahan. Penggunaan LPT tidak disarankan pada awal penjadwalan, karena stasiun kerja menjadi menganggur.

Artificial Neural Network (ANN) merupakan model penalaran yang didasarkan pada otakmanusia. ANN terdiri dari sejumlah prosesor sangat sederhana dan saling berhubungan yang disebut neuron. Neuron yang terhubung dengan pembobotan (weight) melewati sinyal dari neuron satu ke neuron yang lain. ANN mampu mengenalisinyal input yang agak berbeda dari yang pernah diterima sebelumnya dan mampu bekerja meskipun beberapa neuronnya tidak mampu bekerja dengan baik. Jika sebuah neuron rusak maka neuron lain dapat dilatih untuk menggantikan fungsi neuron yang rusak tersebut (Raharjo, 2013).

Model neuron ANN terdiri dari fungsi penjumlah (summing function), fungsi aktivasi (activation function), dan keluaran (output). Cara kerja ANN adalah informasi yang masuk (input) akan dikirim ke neuron dengan bobot tertentu dan selanjutnya diproses oleh suatu fungsi yang akan menjumlahkan nilai-nilai bobot yang ada. Hasil penjumlahan akan dibandingkan dengan nilai ambang (threshold) tertentu melalui fungsi aktivasi setiap neuron. Jika input melewati suatu nilai ambang tertentu, maka neuron akan diaktifkan, jika tidak, maka neuron tidak akan diaktifkan. Neuron yang diaktifkan akan mengirimkan output melalui bobot-bobot outputnya ke semua neuron yang berhubungan dengannya. Struktur ANN terdiridari layer input layer, hidden layer dan output layer (Raharjo, 2013).

Input layer $\left(x_{1}, x_{2}, x_{3}, \ldots, x_{n}\right)$, terdiri dari unit-unit input. Unit-unit input menerima pola inputan data dari luar yang menggambarkan suatu permasalahan. Hidden Layer $\left(h_{1}, h_{2}, . ., h_{n}\right)$, terdiri dari unit-unit tersembunyi. Di mana outputnya tidak dapat secara langsung diamati. Sedangkan Output Layer $\left(y_{1}, \ldots, y_{n}\right)$ terdiri dari unit-unit output yang 
merupakan solusi ANN terhadap suatu permasalahan.

Model ANN umumnya menggunakan Algoritma Back Propagation (BP) yang merupakan pengembangan dari algoritma least mean square untuk melatih jaringan dengan beberapa layer. BP (Back Propagation menggunakan pendekatan algoritma steepest descent dengan performance indexnyaa dalah mean square error (MSE). Dalam melatih jaringan diperlukan seperangkat pasangan data seperti berikut:

$\left\{p_{1}, t_{1}\right\},\left\{p_{2}, t_{2}\right\} \rightarrow\left\{p_{n}, t_{n}\right\}$

Di mana $\boldsymbol{p}_{\boldsymbol{n}}$ adalah nilai input ke-n jaringan dan $\boldsymbol{t}_{\boldsymbol{n}}$ adalah target, yaitu nilai output yang seharusnya dihasilkan. Algoritma yang akan mengatur atau menyesuaikan parameterparameter jaringan dalam meminimalkan mean square error, yaitu:

$\boldsymbol{o}_{k}=\boldsymbol{f}\left(\boldsymbol{n e t}_{\boldsymbol{k}}\right)=\boldsymbol{f}\left(\sum_{k} \boldsymbol{W}_{j k} \boldsymbol{o}_{j}+\boldsymbol{\theta}_{\boldsymbol{k}}\right.$

Di mana $\mathrm{O}_{\mathrm{k}}$ adalah output dari neuron $\mathrm{k}$, Oj adalah output dari neuron j pada lapisan yang lebih rendah, $\mathrm{W}_{\mathrm{jk}}$ adalah bobot antara neuron $\mathrm{k}$ dan j, net $\mathrm{k}_{\mathrm{k}}$ merupakan net input yang masuk keneuron $\mathrm{k}$ dari lapisan yang lebih rendah, $\Theta \mathrm{k}$ adalah bias untuk satuan $k$ dan $f(.$.$) adalah$ fungsi aktivasi neuron. Kemudian fungsi kesalahan minimal yang digunakan BP pada lapisan keluaran adalah jumlah kuadrat ratarata kesalahan $\mathrm{E}$, didefinisikan:

Error, $E=\frac{1}{2} \sum_{k}\left(t_{k}-o_{k}\right)^{2}$

Di mana $t_{k}$ adalah target output dan $0_{k}$ adalah hasil yang aktual dari neuron. Berdasar penurunan gradien, maka setiap perubahan bobot harus sebanding dengan gradien negatif dari penyimpangan terhadap bobot tertentu:

$\Delta W=-\eta \frac{\partial E}{\partial W}$

Di mana $\eta$ adalah konstanta yang mewakili learning rate. Semakin besar $\eta$, semakin besar perubahan bobot, sehingga semakin cepat bobot yang diinginkan ditemukan. Tetapi jika $\eta$ terlalu besar, akan dapat menyebabkan osilasi Deferensiasi dari fungsi E merupakan penyimpangan terhadap bobot W dalam persamaan di atas sebanding dengan turunan pertama dari fungsi aktivasi, yaitu :

$$
\frac{\partial E}{\partial W} \infty f^{\prime}(n e t)
$$

Perubahan bobot paling mudah dipahami dengan membedakan antara komponen

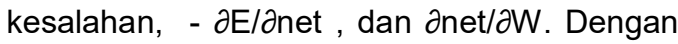
demikian kesalahan untuk output neuron adalah :

$$
\begin{aligned}
\delta_{k} & =-\frac{\partial E}{\partial 0_{k}} \frac{\partial 0_{k}}{\partial \text { net }_{k}} \\
& =\left(t_{k}-o_{k}\right) f^{\prime}\left(o_{k}\right)
\end{aligned}
$$

Dan untuk hidden neuron adalah :

$\delta_{k}=\left(-\frac{\partial E}{\partial 0_{k}} \frac{\partial o_{k}}{\partial \text { net }_{k}} \frac{\text { nnet }_{k}}{o_{j}}\right) \frac{\partial o_{j}}{\partial \text { net }_{j}}$

$=\sum_{k} \boldsymbol{\delta}_{k} \boldsymbol{W}_{\boldsymbol{j} k} \boldsymbol{f}^{\prime}\left(\boldsymbol{o}_{j}\right)$

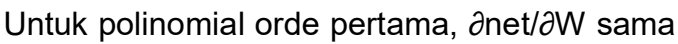
dengan aktivasi input. Perubahan beban untuk beban ouput secara sederhana adalah :

$$
\Delta W_{j k}=\eta \delta_{k} o_{j}
$$

Sedangkan untuk beban input, adalah :

$$
\Delta W_{i j}=\eta \delta_{j} o_{i}
$$

Particle Swarm Optimization (PSO) terinspirasi pada perilaku sosial koloni hewan seperti rayap, lebah, ikan atau burung. Perilaku sosial ini terdiri dari tindakan individu dan pengaruh dari individu-individu lain dalam suatu kelompok. Setiap individu berperilaku secara terdistribusi dengan menggunakan kecerdasannya (intelligence) sendiri dan juga dipengaruhi kelompok kolektifnya. Misalnya, jika seekor burung menemukan jalan yang tepat (optimal) menuju sumber makanan, maka sisa anggota kelompok yang lainnya juga akan mengikuti jalan tersebut meskipun 
lokasi mereka didalam kelompok tersebut tidak saling berdekatan (Raharjo, 2013).

PSO dikembangkan berdasarkan pada model tersebut, di mana ketika partikel mendekati target minimum atau maksimum dari fungsi tujuan, partikel tersebut akan secara cepat mengirim informasi kepada partikel yang lainnya dalam kawanan tertentu sehingga partikel yang lain akan mengikuti arah menuju ke target nilai tersebut tetapi tidak secara langsung.

Ada satu komponen yang bergantung pada memori dari setiap partikel yaitu memori tentang apa yang sudah dilalui sebelumnya. Jika jalur tersebut pernah dilalui dan ternyata tidak menghasilkan nilai sesuai fungsi tujuan maka jalur tersebut tidak akan diikuti.

Model ini disimulasikan dalam ruang berdimensi tertentu dengan sejumlah iterasi yang menyebabkan posisi akan semakin mengarah ke target nilai fungsi tujuan. Dalam setiap iterasi, partikel akan menyimpan solusi terbaiknya yang disebut sebagai pbest (personal best). Sedangkan solusi terbaik untuk semua partikel disebut sebagai gbest (global best) juga akan selalu digunakan. Proses pergantian posisi partikel didasarkan pada kecepatan (velocity) masing-masing partikel menuju pbest dan gbest (Kennedy dan Eberhart, 2001).

Dalam PSO, pencarian solusi optimal akan dilakukan sampai semua partikel memiliki skema solusi yang sama atau ketika iterasi maksimum sudah tercapai. Formulasi untuk update kecepatan dan posisi pada iterasi selanjutnya adalah sebagai berikut (Raharjo, 2013):

$$
\begin{gathered}
V_{k+1}=V_{k}+c_{1} \cdot R_{1} \cdot\left(\text { Pbest }_{k}-X_{k}\right)+ \\
c_{2} \cdot R_{2} \cdot\left(\text { Gbest }_{k}-X_{k}\right) \\
X_{k+1}=X_{k}+V_{k+1 \ldots \ldots \ldots \ldots(10)}
\end{gathered}
$$

Dengan, $k: 1,2,3, \ldots, N ; \quad V_{k+1}$ : kecepatan untuk posisi yang dituju; $V_{k}$ : kecepatan untuk posisi sekarang (awal); Pbest Gbest $t_{\mathrm{k}}$ : Global best; $c_{1}, c_{2}$ : learning rates. Untuk kemampuan individu dan pengaruh sosial group yang menunjukan bobot dari memori sebuah partikel terhadap memori dari kelompoknya, nilai dari $c_{1}, c_{2}$ biasanya merupakan konstanta dengan nilai $c_{1}=2$ dan $c_{2}=2 ; \quad R_{1}, R_{2}$ : angka acak antara 0 dan 1 ;
$X_{k+1}$ : Posisi yang dituju; $X_{k}$ : Posisi sekarang. Berikut ini adalah prosedur PSO:

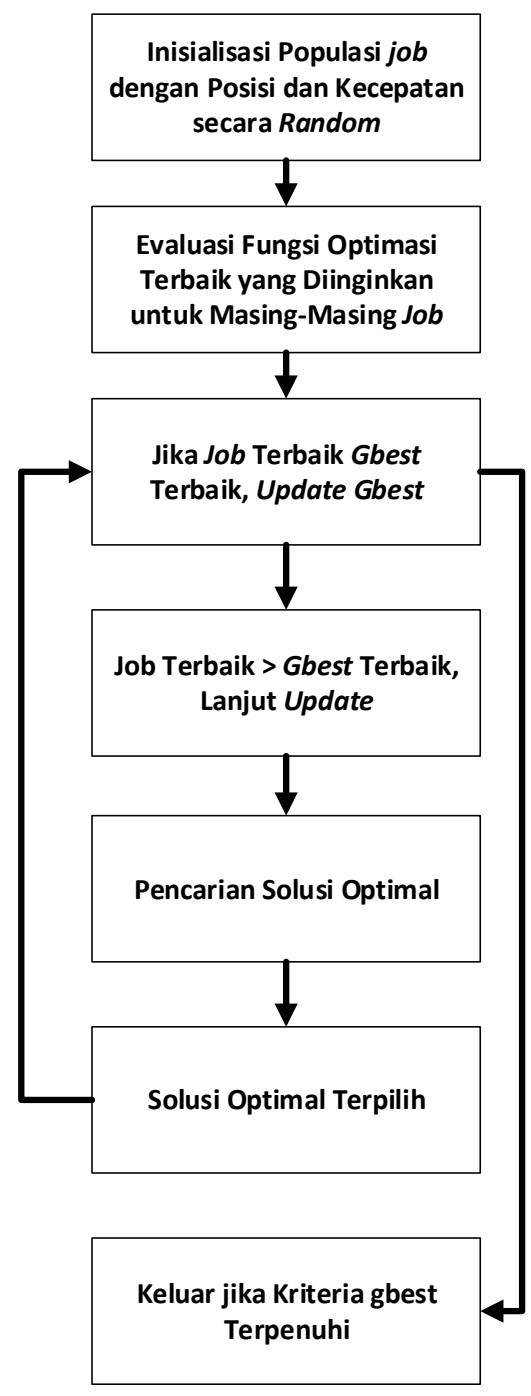

Gambar 1. Prosedur PSO

Menurut Mauluddin dkk. (2016) metode algoritma Steepest Ascent Hill Climbing (pencarian bukit) merupakan salah satu metode pencarian yang proses pengujiannya menggunakan fungsi heuristik. Metode ini berbeda dengan metode pembangkitan \& pengujian (Generate \& Test), dimana umpan balik prosedur pengujian yang dilakukan untuk membantu menentukan solusi yang bisa langsung di hilangkan dalam ruang pencarian. Oleh karena itu, pembangkitan keadaan berikutnya sangat tergantung pada umpan balik dari prosedur pengetesan. Ada 
dua macam metode hill climbing, yaitu simple hill climbing dan steepest ascent hill climbing.

Steepest Ascent Hill Climbing merupakan metode algoritma yang banyak digunakan untuk permasalahan optimasi. Salah satu penerapannya adalah untuk mencari rute yang terpendek dengan cara memaksimumkan atau meminimumkan nilai dari fungsi optimasi yang ada. Secara harfiah steepest berarti paling tinggi, sedangkan ascent berarti kenaikan. Dengan demikian steepest ascent berarti kenaikan paling tinggi. Jadi prinsip dasar dari metode ini adalah mencari kenaikan paling tinggi dari keadaan sekitar untuk mencapai nilai yang paling optimal (Kusumadewi, 2003).

Bedanya adalah simple hill climbing menentukan next state dengan membandingkan current state (titik awal) dengan satu successor (titik persimpangan) dan successor pertama yang lebih baik akan dipilih menjadi next state. Sedangkan steepest ascent akan membandingkan current state dengan semua succesor yang ada didekatnya sehingga dalam steepest ascent hill climbing, next statenya merupakan successor yang paling baik atau paling mendekati tujuan (Uriawan dkk, 2015).

Metode Steepest Ascent Hill Climbing, menggunakan algoritma sebagai berikut ini (Zemma dan Our, 2015):

1. Mulai dari keadaan awal, lakukan pengujian, jika merupakan tujuan maka berhenti, dan jika tidak lanjutkan dengan keadaan sekarang sebagai keadaan awal.

2. Kerjakan hingga tujuan tercapai atau hingga iterasi tidak memberikan perubahan pada keadaan sekarang.

a. Misalkan SUCC adalah suatu state yang menjadi suksesor dari current state.

b. Untuk setiap operator bisa dilakukan terhadap current state, kerjakan:

1) Aplikasi operator tersebut dan bangkitkan new state.

2) Evaluasi new state. Jika merupakan goal state, kembalikan state ini sebagai solusi dan keluar dari program. Jika bukan goal state, bandingkan new state dengan SUCC. Jika new state lebih baik dari SUCC, maka ganti SUCC dengan new state. Jika tidak lebih baik SUCC tidak perlu diganti.

c. Jika SUCC lebih baik dari current state, maka ganti current state dengan SUCC. Pada Steepest Ascent Hill Climbing, ada tiga masalah yang mungkin terjadi, yaitu:

1) Local Optimum: keadaan semua tetangga lebih buruk atau sama dengan keadaan dirinya.

2) Plateu: keadaan semua tetangga sama dengan keadaan dirinya.

3) Ridge: local optimum yang lebih disebabkan karena ketidak mampuan untuk menggunakan dua operator sekaligus.

Menurut (Waskita dkk, 2016) dalam penelitian yang dilakukan terdapat dua constrain yaitu hardconstrain dan soft constrain. Hardconstrain merupakan ketentuan yang tidak boleh dilanggar dan soft constrain merupakan ketentuan yang memiliki toleransi untuk dilanggar, namun tetap diharapkan tidak melanggar ketentuan tersebut.

Hard constrain penjadwalan adalah produksi Tortilla tidak dapat diproduksi dalam satu waktu dengan varian rasa dan gramatur yang berbeda. Perbedaan rasa dan gramatur disebabkan karena produksi yang dilakukan berdasarkan seasoning dan berat kemasan berbeda pada setiap jenis Tortilla Setiap produksi harus dilakukan satu kali waktu dengan jumlah produksi yang telah ditentukan oleh PPIC. Pada penelitian ini hard constrain dicek pada saat akan memulai membuat jadwal produksi. Sedangkan soft constrain jadwal produksi adalah proses produksi harus 1 varian dan gramatur yang tetap untuk memproduksi satu jenis Tortilla. Dua softconstrain tersebut merupakan kriteria untuk menentukan kualitas jadwal. Rumus untuk menghitung kualitas jadwal $\left|f_{(\text {opt) }}\right|$ akan dijelaskan sebagai berikut (Waskita dkk, 2016):

Pertama mencari $\bar{X}$ (rata-rata produksi) dari persamaan (11) $X_{i}$ (varian) dan $\mathrm{n}$ (jumlah produksi) untuk digunakan mencari $f(p s)$ (fungsi produksi satuan).

$\bar{x}=\frac{\sum_{i}^{n} X_{i}}{n}$ 
Kedua, hasil dari $\bar{X}$ digunakan untuk mencari $\mathrm{f}(\mathrm{ps})$ dari persamaan (12) dengan $\mathrm{p}_{\mathrm{s}}$ (produksi/hari) $\mathrm{X} \quad$ (banyak minggu produksi/bulan), $\mathrm{P}_{1}$ (produksi/hari), dan $\mathrm{n}$ (banyak minggu/bulan).

$f(p s) \frac{\sqrt{\sum_{i=1}^{n}\left(\bar{X}_{1}-X\right)^{2}}}{n-1}$

Ketiga, mencari nilai $f\left(p_{s}\right)$ menggunakan persamaan (13).

$f\left(p_{s}\right) \frac{\sum_{i=1}^{n} \mathrm{P}_{1}}{n}$

Keempat, mencari $f$ (opt) (fungsi objektif penjadwalan tortilla) menggunakan persamaan (14) dengan C (nilai penyerataan).

$f(o p t)=\frac{C_{1} X f_{p s}+C_{2} X f_{p s 2}}{C_{1}+C_{2}}$

Hasil pengoptimalan dengan 4 persamaan tersebut menghasilkan penurunan dalam nilai persentase. Pemilihan metode Steepest Ascent Hill Climbing untuk mencari solusi pengoptimalan setelah menggunakan Artificial Neural Network berbasis Particle Swarm Optimization.

\section{METODE PENELITIAN}

Penelitian dilakukan dengan observasi langsung dengan studi literatur beberapa jurnal dan penelitian terkait metode ANNPSO-SAHC sebagai berikut:

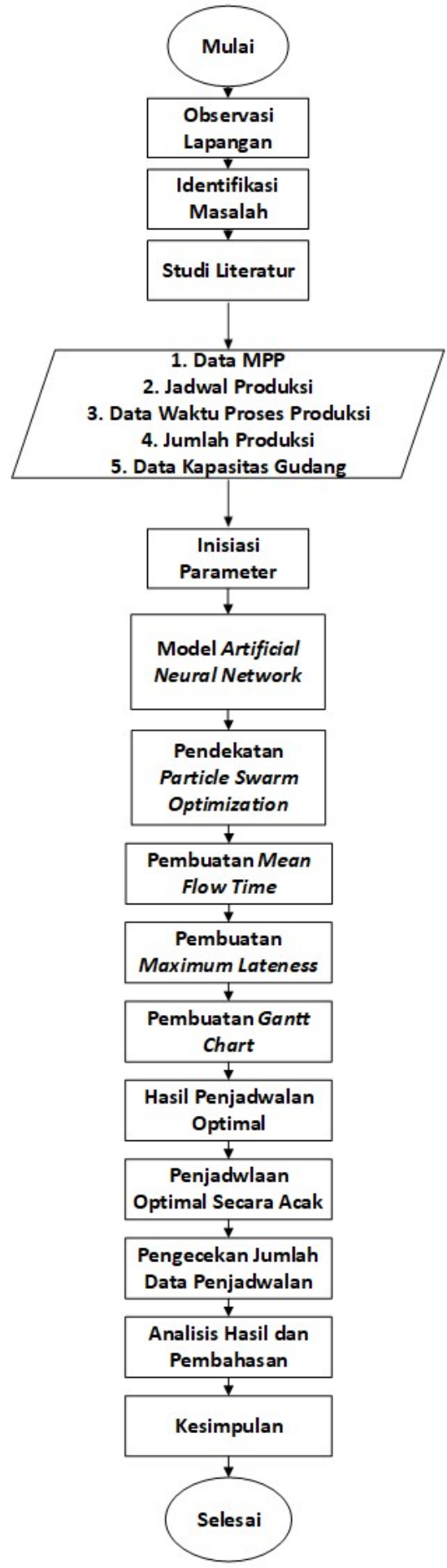

Gambar 2. Diagram Alir Penelitian

\section{HASIL DAN PEMBAHASAN}

Hasil pengolahan data dengan pembahasan pada makespan dan mean flow time. Pembahasan makespan dari metode Perusahaan dan Artificial Neural Network Berbasis Particle Swarm Optimization 
Menggunakan Algoritma Steepest Ascent Hill Climbing digunakan untuk mengetahui perbedaan pengoptimalan, menekankan pada hasil yang lebih optimal dari kedua metode yang sudah diolah. Setelah proses perhitungan selesai pada tahap sebelumnya, menjelaskan bahwa ada dua perbandingan metode dalam mengukur makespan. Hasil yang diperoleh juga sangat bervariasi, dalam analisis perhitungan tersebut pada existing method mempunyai makespan rata-rata 4 hari, makespan rata-rata metode Artificial Neural Network Berbasis Particle Swarm Optimization 3 hari dengan penyelesaian ratarata jumlah produksi pada setiap bulan agar tidak terjadi overproduction. Pengurangan makespan meyakinkan bahwa menggunakan metode Artificial Neural Network Berbasis Particle Swarm Optimization lebih optimal dan berperan penting dalam meminimalisir makespan dan overproduction dibandingkan dengan metode Artificial Neural Network Berbasis Particle Swarm Optimization. Hasil dari pengoptimalan dioptimalkan kembali untuk mengetahui besar pengoptimlan terbaru untuk mengurangi dampak overproduction

Hasil pengolahan ANN-PSO-SAHC didapat penurunan pada bulan Mei dan Juni sebesar 0,5 hari dan pada bulan Juli sebesar 0,1 hari agar dapat mengurangi overproduction. Pengurangan sebesar 0,5 berdampak pada penjadwalan produksi yang lebih singkat dengan memproduksi varian rasa yang sedang atau sangat dibutuhkan saja sehingga angka overproduction dapat ditekan, sebagaimana pada Gambar 3:

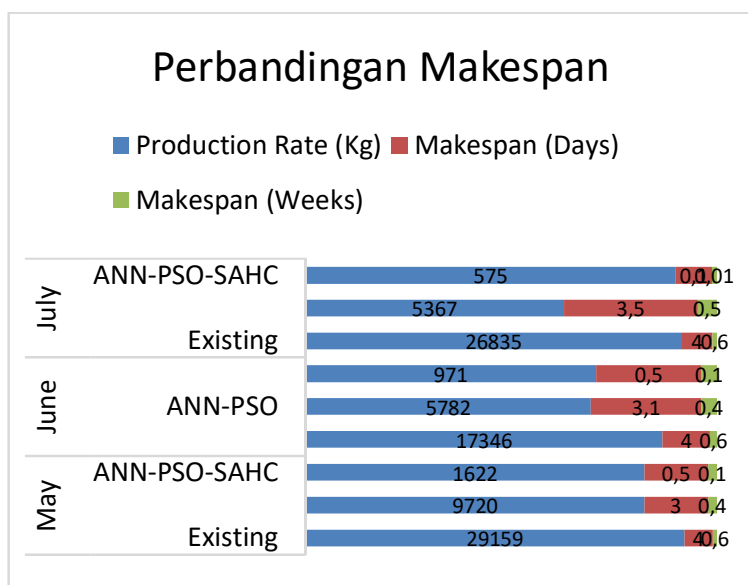

Gambar 3. Histogram Perbandingan Makespan pada Bulan Mei-Juli 2019
Hasil histogram menunjukan bahwa penyelesaian dengan penambahan presentase lebih banyak apabila produksi dilakukan memiliki jumlah produksi total yang lebih rendah seperti pada bulan Mei dan Juni 2019, apabila semakin tinggi jumlah produksinya maka penurunannya semakin sedikit seperti pada bulan Juli 2019.

Hasil penurunan ANN-PSO-SAHC sebesar 0,1-0,5 berdampak pada penjadwalan produksi yang lebih cepat selesai lebih awal, sehingga pada akhir minggu dapat dilanjutkan produksi untuk minggu yang akan datang, berikut hasil penjadwalan produksi menggunakan ANNPSO dilanjutkan menjadi ANN-PSO-SAHC seperti pada Gambar 4:

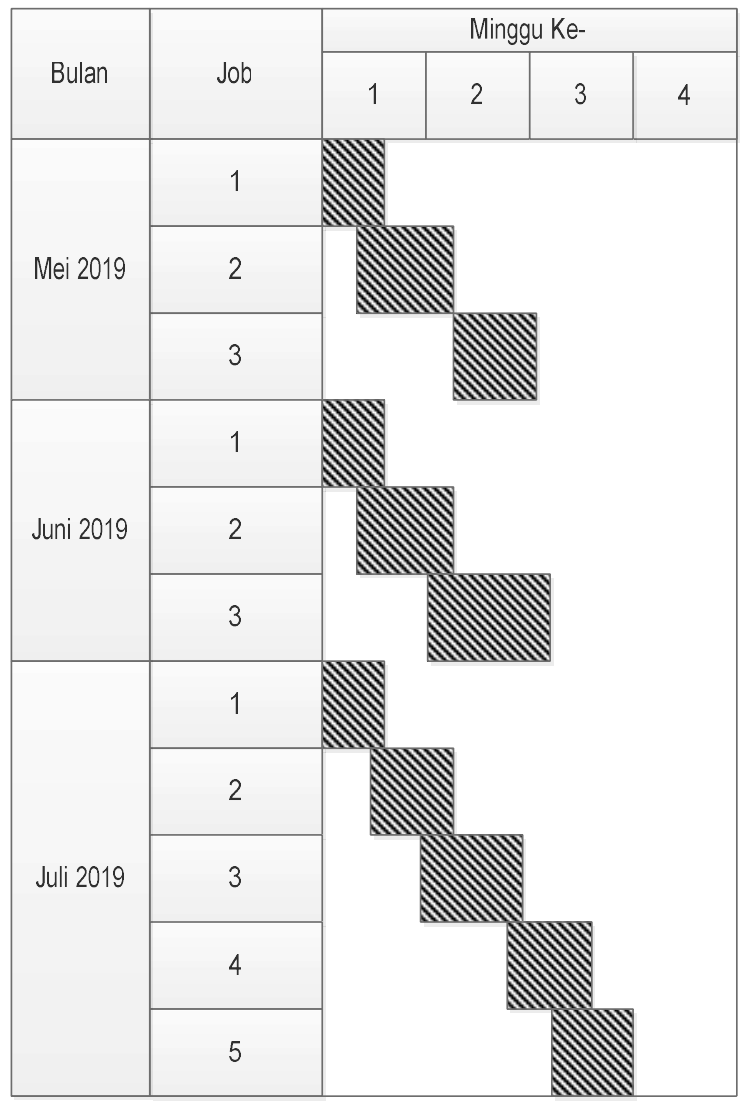

Gambar 4. Jadwal Produksi Metode Artificial

Neural Network Berbasis Particle Swarm

Optimization Menggunaakan Algoritma

Steepest Ascent Hill Climbing

Bulan Mei - Juli 2019

Penurunan intensitas penjadwalan yang cukup signifikan terjadi karena pemilihan varian rasa Tortilla yang sedang atau banyak 
digemari di waktu tertentu dapat menjadi solusi masalah overproduction, sehingga tidak mengurangi atau menambah penjadwalan, namun pemilihan prioritas penjadwalan lebih awal dan diurutkan sesuai kebutuhan pada varian rasa Tortilla.

Hasil Perbandingan Mean Flow Time dari Existing Method dan Artificial Neural Network Berbasis Particle Swarm Optimization Menggunakan Algoritma Steepest Ascent Hill Climbing. Pembahasan mean flow time dari metode Perusahaan dan Artificial Neural Network Berbasis Particle Swarm Optimization Menggunakan Algoritma Steepest Ascent Hill Climbing digunakan untuk mengetahui terdapat perbedaan pengoptimalan, menekankan pada hasil yang lebih optimal dari kedua metode yang sudah diolah. Berikut histogram pada Gambar 5:

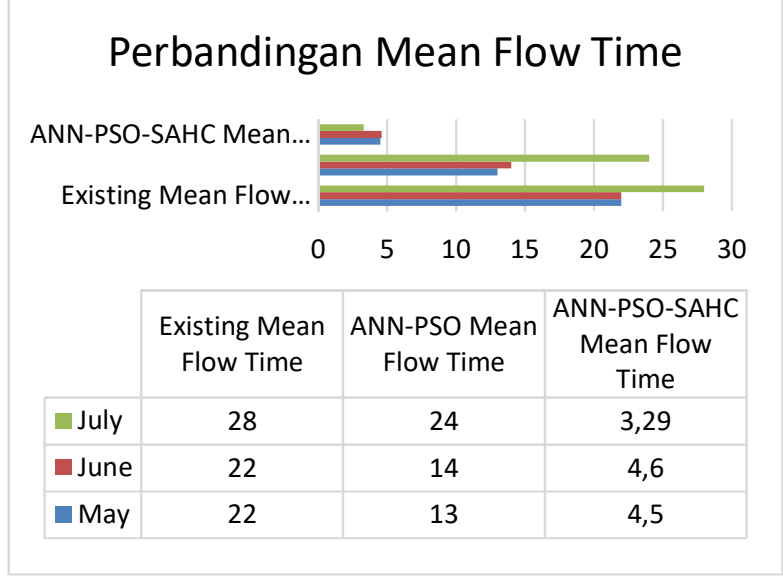

Gambar 5. Histogram Perbandingan Mean

Flow Time pada Bulan Mei-Juli 2019

Setelah proses perhitungan selesai pada tahap sebelumnya, menjelaskan bahwa ada dua perbandingan metode dalam mengukur mean flow time. Hasil yang diperoleh berupa minimalisir sebesar 10\% setelah digunakan Steepest Ascent Hill Climbing. Hasil pengoptimalan didapat sebesar $51 \%$ dengan awal menggunakan metode ANN-PSO sebesar $41 \%$ dan ditambah SAHC sebesar $10 \%$, sehingga penambahan pengoptimalan metode ANN-PSO-SAHC menjadikan penjadwalan dapat lebih optimal. Berikut hasil perbandingan mean flow time pada Gambar 6:

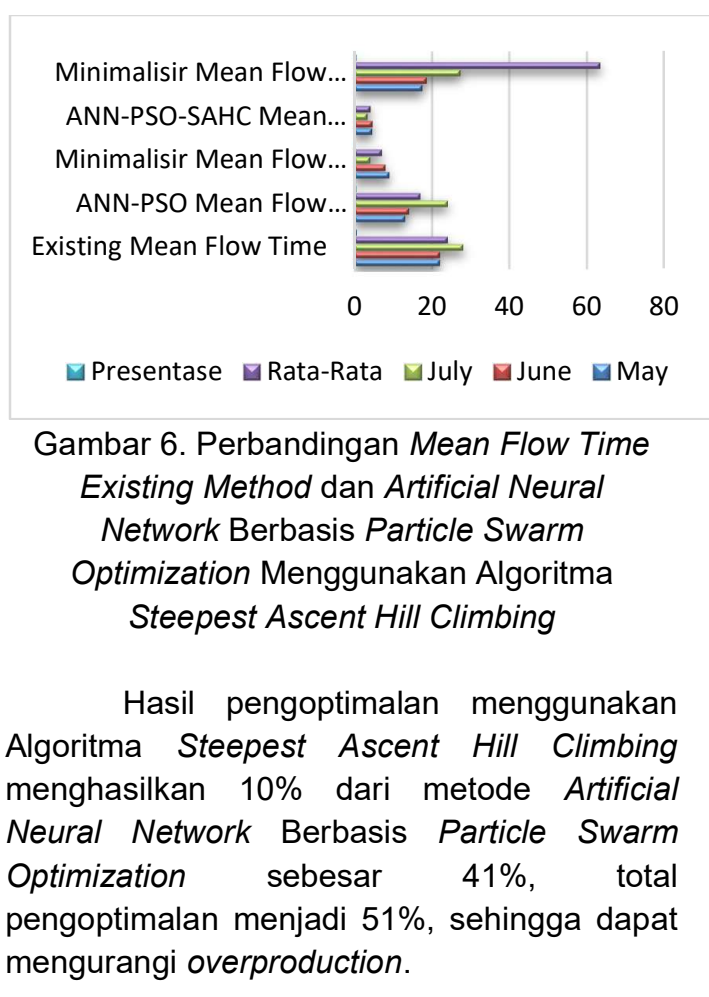

\section{SIMPULAN}

Hasil dari perhitungan existing method menunjukan adanya kelebihan mean flow timelateness, dan makespan pada setiap minggu dalam tiap bulan yang menyebabkan overproduction dan waktu produksi lebih lama, sehingga perlu dilakukan perubahan. Penerapan metode Artificial Neural Network Berbasis Particle Swarm Optimization menggunakanAlgoritma Steepest Ascent Hill Climbing dengan memodelkan jumlah produksi dengan memilih jumlah rata-rata seluruh produksi setiap minggu dapat meminimalkan overproduction dan didapat kesimpulan sebagai berikut:

1. Pengoptimalan Mean Flow Time dan Penurunan Lateness

Hasil mean flow time akhir sebesar $51 \%$, pengurangan makespan sebesar 0,5 pada bulan Mei-Juni dan 0,1 pada bulan Juli. Pengurangan makespan pada bulan Mei dan Juni dapat dilakukan penjadualan ulang agar dapat mengurangi overproduction.

Penurunan lateness sebesar $17 \%$ setelah menggunakan ANN-PSO ditambah penurunan menggunakan ANN-PSO-SAHC bertambah $13 \%$ 
menghasilkan pengurangan keterlambatan apabila diterapkan dan dilakukan pengoptimalan sehingga dapat menjadi solusi mengatasi masalah overproduction.

2. Hasil Uji Pemodelan

Hasil dari perhitungan metode Artificial Neural Network Berbasis Particle Swarm Optimization menggunakan Algoritma Steepest Ascent Hill Climbing menghasilkan penurunan mean flowtime dan lateness sebesar $51 \%$ dan $13 \%$ serta pengurangan makespan sebesar 3-4 hari dalam setiap minggu dalam proses produksi dapat menurunkan overproduction dengan melakukan produksi pada jumlah rata-rata setiap satu bulan.

Jumlah produksi terendah dan tertinggi pada jumlah keseluruhan setiap bulan dapat diselesaikan dalam satu minggu dengan melakukan pengoptimalan pada jumlah ratarata produksi setiap minggu dan bulan sehingga menghasilkan penjadwalan baru dengan jumlah lebih minimal dalam perusahaan dengan risiko overproduction lebih kecil.

\section{DAFTAR PUSTAKA}

Amras. M, H. Prasetyo, dan S. A. Dewi. 2016. Implementasi Algoritma Steepest Ascent Hill Climbing Pada Permainan Slide Puzzle Berbasis Android. ProsidingSeminar Nasional Teknologi Informasi dan Komunikasi. Yogyakarta.

Bedworth, D.D dan Bailey, J.E. 1982. Integrated Production Control System Management, Analysis, Design. John Wiley and Son Inc., New York

D. E. Rumelhart, G. E. Hinton, and R. Williams, 1986 "Learning internal representations by error propagation.," Paralled Distributed Processing: Explorations in the Microstructure of Cognition, vol. 1, pp. 318-362

Fiqihesa P., B. Santosa, dan N. Siswanto. 2014. Penyelesaian Permasalahan Multi-Objective Hybrid Flow Shop Schedulingdengan Algoritma Modified Particle Swarm Optimization. Prosiding Seminar Nasional Manajemen
Teknologi XXI. ISBN: 978-602-70604-01.

Hana, D.M. dan W.R. Newman. 2001. Integrated Operation Management Adding Value For Customers. PrenticeHall, Inc, New Jersey.

Heizer, J. dan B. Render. 2005. Production and Operation Management. Allyn and Bacon, Boston.

Hendra, W., H. D. Purnomo., Hendry. 2016. Penjadwalan Kelas Praktikum Menggunakan Algoritma Steepest Ascent Hill Climbing. Jurnallnnovative and Creative Information Technology Conference (ICITech). Salatiga. Vol 13 No.2.

J. E. Biegel, 1992 Pengendalian Produksi Suatu Pendekatan Kuantitatif. Jakarta: Akademika Pressindo,

Joko. S dan D Raharjo, 2013. Model Artificial Neural Network Berbasis Particle Swarm Optimation Untuk Prediksi Laju Inflasi. Jurnal Sekolah Tinggi Manajemen Informatika dan Komputer Eresha. Jakarta. Vol 3 No.1.

K. R. Baker and D. Trietsch, 2013 Principles of sequencing and scheduling: John Wiley \& Sons.

Kusumadewi, S. (2003). Artificial Intelligence. Jogyakarta: Graha IImu

Mahmudy, WF 2014, Optimasi Part Type Selection and Machine Loading Problems Pada FMS Menggunakan Metode Particle Swarm Optimization', Konferensi Nasional Sistem Informasi (KNSI), STMIK Dipanegara, Makassar

Muhamad, H., Prasojo, C. A., Sugianto, N. A., Surtiningsih, L., Cholissodin, I. 2017. Optimasi Naïve Bayes Classifier Dengan Menggunakan Particle Swarm Optimization Pada Data Iris. Jurnal Teknologi Informasi Dan IImu Komputer (JTIIK)

Putranto, K. N. 2012. Perancangan dan Implementasi Penjadwalan Mata Kuliah Menggunakan Algoritma Sttepest Ascent Hill Climbing (Studi Kasus: Fakultas Psikologi UKSW). Universitas Kristen Satya Wacana Salatiga

R. W. Conway, W. L. Maxwell, and L. W. Miller, 2003. Theory of scheduling: Courier Corporation. 
Rachman R. 2018. Penjadwalan Produksi Harment Menggunakan Algoritma Heuristic Pour. Jurnal Informatika Vol 5 No 1

Shoffan S. 2015. Pengembangan Sistem Penjadwalan Mata Kuliah Mahasiswa Menggunakan Algoritma Steepest Ascent Hill Climbing(Studi Kasus: Fakultas Sains dan Teknologi Universitas Teknologi Yogyakarta). Skripsi. Program Studi Teknik Informatika Universitas Teknologi Yogyakarta. Yogyakarta

Salnan. R.A., H.S Dachlan., E. Yudaningtyas., 2015. Optimasi Training Neural Network Menggunakan Hybrid Adaptive Motion PSO-BP. Jurnal EECCIS Vol 9 No 1.

Sumayang, L. 2003. Dasar-Dasar Manajemen Produksi dan Operasi. Salemba Empat, Jakarta.

Uriawan, W., Faroqi, A., Fathonah, R., Informatika, J. T., Sains, F., \& Negeri, U. I. (2015). Game slider puzzle. Pembuatan Game Slider Puzzle Menggunakan Metode Steepest Ascent Hill Climbing Berbasis Android, IX(1), 204-221.

Waratati. D dan M. N. Aini. 2016. Aplikasi Jaringan Saraf Tiruan dan Particle Swarm Optimization Untuk Peramalan Indeks Harga Saham Bursa Efek Indonesia. Jurnal TECHNOSAINS. Vol 6 No 1.

Xue, B., Zhang, M., Member, S., \& Browne, W. N. 2012. Particle Swarm Optimization for Feature Selection in Classification: A Multi Objective Approach. leee Transactions on Cybernetics.

Zakiah, A., \& Masalah, R. 2012. Penyelesaian Masalah 8 Puzzle Dengan Algoritma Hill Climbing, (Sentika), 158-163.

Zemma, L. A., Herfina, \& Qur, A. 2015. Penerapan Metode Steepest Ascent Hill Climbing Pada Model Pencarian Rute Terdekat Fasilitas Pelayanan Darurat di Kota Bogor Berbasis Android. 